\title{
Surface water organophosphorus pesticides concentration and distribution in the Langat River, Selangor, Malaysia
}

\begin{abstract}
Pesticide contamination in the environment is a contemporary global issue. As agricultural production through crop planting in Malaysia now supports both energy and food productions, the concentration and distribution of pesticides in surface water may have changed. Therefore, this study assesses the concentration and distribution of organophosphorus pesticides (quinalphos, diazinon and chlorpyrifos) contamination in the Langat River, Selangor. The Langat River Basin is one of the most populated river basins in Malaysia. As a result, it is surrounded by various environmental stresses of which agricultural activity is a dominant cause. An analytical method has been developed and optimised based on solid-phase extraction and high-performance liquid chromatography, coupled with a diode array detector (SPE-HPLC-DAD). This method allowed for the determination and quantification of selected organophosphorus pesticides. The optimised method displays a high mean recovery for both quinalphos and diazinon (100.21 and $100.15 \%$, respectively) but relatively low recovery for chlorpyrifos $(32.40 \%)$. The low recovery of chlorpyrifos is due to limitations in the determination of multi-residues in a single analytical run, optimisation of chromatographic conditions and the recovery of each compound. The method detection limit was found to be $0.003 \mu \mathrm{g} / \mathrm{L}$ for quinalphos and diazinon, and $0.006 \mu \mathrm{g} / \mathrm{L}$ for chlorpyrifos. Sample analyses revealed the occurrence of quinalphos, diazinon and chlorpyrifos in the Langat River with chlorpyrifos found to have the highest mean concentration of $0.0202 \mu \mathrm{g} / \mathrm{L}$. The quinalphos and diazinon sample concentrations were $0.0178 \mu \mathrm{g} / \mathrm{L}$ and $0.0094 \mu \mathrm{g} / \mathrm{L}$, respectively. The concentrations of organophosphorus pesticides in this monitoring study were found to be below the Maximum Contaminant Levels (MCLs) established under the European Union (Drinking Water) Regulation 2014. This study was the first to detect concentrations of quinalphos and diazinon in the Langat River, Selangor.
\end{abstract}

Keyword: Organophosphorus pesticides; Contamination; Surface water; Solid-phase extraction; HPLC-DAD; Langat River Basin 